\title{
Environmental factors act through aryl hydrocarbon receptor activation and circadian rhythm disruption to regulate energy metabolism
}

This article was published in the following Dove Press journal: Journal of Receptor, Ligand and Channel Research

\author{
Ali Q Khazaal ${ }^{1,2}$ \\ Cassie D Jaeger ${ }^{3}$ \\ Kathleen M Bottum ${ }^{4}$ \\ Shelley A Tischkau ${ }^{1,3}$ \\ 'Department of Medical Microbiology, \\ Immunology and Cell Biology, \\ Southern Illinois University School \\ of Medicine, Springfield, IL, USA; \\ Biotechnology Department, College \\ of Science, Baghdad University, \\ Baghdad, Iraq; ${ }^{3}$ Department of \\ Pharmacology, Southern Illinois \\ University School of Medicine, \\ ${ }^{4}$ Department of Internal Medicine, \\ Division of Medicine and Psychiatry, \\ Southern Illinois University School of \\ Medicine, Springfield, IL, USA
}

\begin{abstract}
Disruption of energy metabolism, resulting in metabolic illnesses including diabetes, hyperlipidemia, fatty liver, hypertension and atherosclerosis, will likely shorten human life expectancy over the next several decades. Past work focusing on diet and exercise needs to be continued, but new environmental factors such as exposure to pollutants and the disruption of circadian rhythms in modern life urgently need more attention and understanding. This review focuses on how environmental pollutants acting through the aryl hydrocarbon receptor (AhR) to cause circadian disruption lead to metabolic derangements. AhR-mediated metabolic dysregulation in the whole organism, and dysregulation specific to the liver and adipose tissue, will be explored. Finally, the role of AhR in circadian desynchrony and resultant effects on energy metabolism will be discussed. This review summarizes information vital to future developments that can combat metabolic illnesses.
\end{abstract}

Keywords: aryl hydrocarbon receptor, adipogenesis, glucose metabolism, lipolysis, circadian rhythm, insulin sensitivity

\section{Introduction}

For the first time in modern medical history, life expectancy is decreasing. ${ }^{1,2}$ Obesity, insulin resistance and obesity-associated illnesses, including metabolic syndrome, fatty liver, lipid disorders and cardiovascular disease, are major causes of decreasing life span. The Center for Disease Control reports that more than $34.9 \%$ of U.S. adults are obese, ${ }^{3,4}$ and estimates associated yearly medical costs at $\$ 147$ billion dollars. ${ }^{5}$ Obesity initiates alterations in adipose tissue, liver and skeletal muscle that affect energy metabolism and ultimately promote a systemic insulin resistance that leads to development of type 2 diabetes mellitus. Not surprisingly, the rapid worldwide increase in obesity has been accompanied by an equally alarming rise in type 2 diabetes, a metabolic disorder characterized by increased serum glucose secondary to decreased insulin sensitivity. The International Diabetes Foundation estimates that 415 million people currently have diabetes with expectations for an increase to 624 million by 2040 (International Diabetes Federation, 2017 http://www.diabetesatlas.org/).

Although poor diet and lack of physical activity are the most commonly cited contributors to the obesity and diabetes pandemics, these factors alone cannot explain the alarming rates of increase over the past 40 years. Perhaps the most compelling evidence for alternative causes is an increased body weight in wildlife and domestic animals living in developed countries. ${ }^{6}$ Other environmental factors, including exposure to environmental chemicals and alterations in sleep patterns, contribute significantly
Correspondence: Shelley A Tischkau Department of Pharmacology, Southern Illinois University School of Medicine, 80I N. Rutledge, Room 3333, Springfield, IL 62794-9629, USA

Tel +l 2175456524

Email stischkau@siumed.edu (c) (i) (5) 2018 Khazaal et al. This work is published and licensed by Dove Medical Press Limited. The full terms of this license are available at https://www.dovepress.com/terms. BY NC php and incorporate the Creative Commons Attribution - Non Commercial (unported, v3.0) License (http://creativecommons.org/licenses/by-nc/3.0/). By accessing the work you hereby accept the Terms. Non-commercial uses of the work are permitted without any further permission from Dove Medical Press Limited, provided the work is properly attributed. For permission for commercial use of this work, please see paragraphs 4.2 and 5 of our Terms (https://www.dovepress.com/terms.php). 
to the emerging problem of obesity, insulin resistance and diabetes and are the focus of this review.

Obesogens are molecules that change glucose, lipid and protein metabolism, as well as produce changes in feeding behavior that lead to development of obesity and its metabolic sequelae. ${ }^{7,8}$ Certain persistent organic pollutants (POPs) are environmental obesogens, ${ }^{9}$ and epidemiological studies link exposure to these molecules with development of metabolic dysfunction. ${ }^{10,11}$ The relationship is clear for diabetes; exposure to air pollution, airborne fine particulate matter and nitrogen dioxide increases the prevalence of diabetes. ${ }^{12}$ Serum levels of certain POPs are higher in diabetic patients in the Canary Islands, Spain, with a positive correlation observed between serum dichlorodiphenyldichloroethylene and serum glucose levels. ${ }^{13}$ Low levels of insulin are observed in individuals with high serum concentrations of organochlorine pesticides, a type of POPs. Similarly, obesity is more prevalent in children whose mothers were smokers during pregnancy. ${ }^{14}$ Lipid disorders are also affected by POPs. Carbon monoxide, nitrogen dioxide and sulfur dioxide exposure deregulates cholesterol metabolism and reduces high-density lipoproteins and apolipoprotein. ${ }^{15}$ POPs can create liver dysfunction; children exposed to traffic-related air pollution have increased concentrations of plasma cytokeratin-18, a marker of hepatocellular apoptosis and disrupted liver function. ${ }^{16}$ These data suggest a link between exposure to environmental obesogens and metabolic dysfunction. Potential mechanisms for metabolic dysfunction in response to environmental disruptions such as activation of aryl hydrocarbon receptor (AhR) by POPs and circadian rhythm disruption are subsequently explored in this review.

\section{The AhR}

The AhR is an evolutionarily ancient protein that has been studied extensively for its function as a primary mediator of biological responsiveness to xenobiotics, including obesogenic POPs. Industrially produced AhR ligands are toxic chemical contaminants of the global ecosystem, produced as by-products of pesticide production, bleaching and combustion processes. Contamination with these compounds is widespread throughout the biosphere including air, water, fish and mammals. Human studies positively link POPs with obesity and metabolic syndrome. ${ }^{17-21}$

About $90 \%$ of human exposure to obesogens occurs through diet, primarily consumption of animal fat (U.S. EPA, 2004, https://cfpub.epa.gov/ncea/dioxin/recordisplay. $\underline{\mathrm{cfm}}$ ?deid $=87843$ ). In addition to toxic pollutants, compounds that elicit AhR activity are also found in natural dietary products, ${ }^{22-25}$ including indole metabolites from cruciferous plants and flavonoids found in fruits and vegetables. ${ }^{23}$ Thus, AhR can be activated by an array of diverse ligands that can be endogenous, naturally occurring and/or anthropogenic. ${ }^{26-28}$ AhR may alter metabolic function through its regulation of inflammatory cytokine expression, cell cycle signaling and interaction with the cellular circadian clock. ${ }^{29-34}$

AhR is expressed as a cytoplasmic multiprotein complex. ${ }^{35-38}$ Upon activation by high-affinity ligands, a conformational change in the three-dimensional structure of the AhR complex exposes a nuclear localization signal. ${ }^{39}$ Ligandbound AhR translocates to the nucleus, releases ligand and binds to the aryl hydrocarbon nuclear transporter (ARNT). The AhR-ARNT complex binds to specific dioxin response elements (DREs) on the DNA ${ }^{22-40}$ and AhR target genes such as cytochrome P450 (CYP1A1) are expressed (Figure 1). After target gene activation, AhR is removed from the nucleus and degraded by the $28 \mathrm{~S}$ proteasome. ${ }^{39}$ Expression of AhR is also regulated by an inhibitor, the AhR repressor. While this canonical signaling has been identified as a primary mechanism regulating the toxicological responses through $\mathrm{AhR}$, alternative signaling events are increasingly being understood to mediate the physiological effects of AhR. Both cholesterol and fatty acid synthesis are regulated by endogenous AhR activity that does not depend on binding to the DRE. ${ }^{41,42}$ Thus, AhR regulates expression of myriad genes through multiple mechanisms, including many associated with obesity, lipid metabolism and inflammation. ${ }^{41-44}$

\section{Systemic energy metabolism}

AhR activation through POPs and obesogens is linked to the development of type 2 diabetes in humans. Exposure to the strong AhR activator 2,3,7,8-tetrachlorodibenzodioxin (TCDD) is associated with glucose intolerance and hyperinsulinemia; risk of diabetes is positively correlated with TCDD body burden. ${ }^{45-47}$ Vietnam veterans exposed to high levels of Agent Orange causing high AhR activation display hyperinsulinemia and increased type 2 diabetes. ${ }^{48}$

Experimental studies in animal models also demonstrate that AhR activation leads to altered energy metabolism and obesity. Exposure to obesogens suppresses gluconeogenesis and glycogenolysis in mice with a functional $\mathrm{AhR}$; mice without significant AhR activity were unaffected. ${ }^{49} \mathrm{C} 57 \mathrm{BL} / 6$. D2 mice with low-affinity AhR are less susceptible to the negative metabolic impacts of high-fat diet (HFD) exposure compared to $\mathrm{C} 57 \mathrm{BL} / 6$ mice with a high-affinity AhR allele. Increased susceptibility to obesity was hypothesized to be a result of altered peroxisome proliferator-activated receptor 


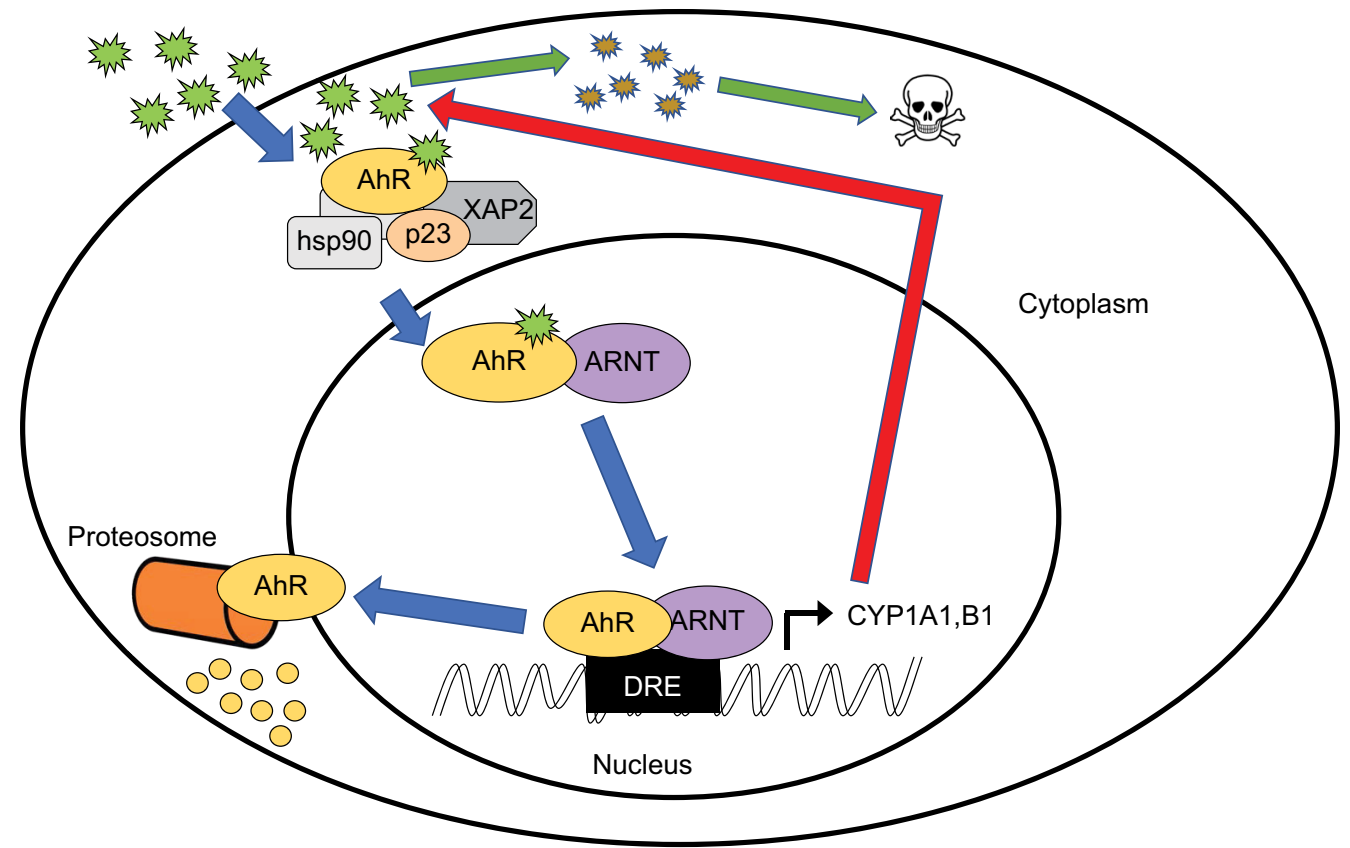

Figure I Canonical AhR signaling pathway.

Notes: Lipophilic POPs enter into cells and bind to the AhR in the cytoplasm where it is associated with a complex of proteins that include hsp90, p23 and XAP. After binding to POPs, AhR dissociates from its chaperone complex and then translocates into nucleus where it forms a heterodimer with ARNT and binds to DRE elements in the promoters of target genes to induce their transcription, including members of the cytochrome P450 family. While expression of the target genes produce phase I metabolizing enzymes that attack POPs and degrade them (red arrow), they also produce cytotoxic metabolites that may have harmful effects on cells (green arrows), the blue arrows indicate the flow of activity that occurs upon activation of the receptor.

Abbreviations: AhR, aryl hydrocarbon receptor; POPs, persistent organic pollutants; ARNT, aryl hydrocarbon nuclear transporter; DRE, dioxin response element.

(PPAR $\alpha, \gamma$, and $\delta$ ) signaling pathways that control lipid metabolism and homeostasis. ${ }^{43}$ AhR activation may inhibit PPAR $\gamma$ function, leading to insulin resistance.$^{50}$ Mechanistic studies in primary and immortalized mouse embryotic fibroblasts isolated from wild-type mice treated with TCDD have suppressed adipogenesis, most likely due to deceased activity of PPAR $\gamma$ and stearoyl-CoA desaturase type 1. TCDD had no effect on fibroblasts isolated from AhR mutant mice..$^{51} \mathrm{AhR}$ deficient mice are unaffected by TCDD, even at doses that are 10-fold higher than those found to induce pathological effects in wild-type littermates, suggesting that the effect is dependent on AhR. ${ }^{52}$

Mice that express a low-affinity AhR allele are less susceptible to obesity after exposure to HFD, exhibiting differences in fat mass, liver physiology and liver gene expression compared to mice with high-affinity AhR. ${ }^{43}$ Similarly, germ line AhR null mice have enhanced insulin sensitivity and improved glucose tolerance. ${ }^{44}$ Even mice that express only a single $\mathrm{AhR}$ allele $\left(A h R^{+-}\right)$, which may in some ways be more similar to the mice with the low-affinity allele, are resistant to the harmful effects of HFD-induced obesity. ${ }^{30}$ The $A h^{-/}$mice have increased basal metabolic rates, accompanied by increased expression of thermogenic genes, including uncoupling protein 1 in brown adipose tissue, and elevated $\beta$-oxidation in skeletal muscle. ${ }^{30}$ Thus, reduced AhR activity may promote enhanced metabolic rate through effects on brown adipose tissue and skeletal muscle.

Fibroblast growth factor 21 (FGF21) is a recently discovered hormone with protective properties against metabolic disease; working independently from the action of insulin, FGF21 promotes glucose uptake, improves lipids metabolism and causes increased energy expenditure and weight loss. ${ }^{53}$ FGF21 is an AhR target gene whose promoter contains several DREs. ${ }^{54,55}$ In the absence of AhR agonist, liver and blood FGF21 levels are higher in mice with liver-specific knockouts of AhR, suggesting that endogenous AhR activity suppresses FGF21. ${ }^{55}$ By contrast, TCDD activation of AhR produced increased liver FGF21 in mice with a normal AhR, but not in AhR null mice. Interestingly, the AhR null mice died within 20 days, while the wild-type control lived to the end of the 30-day experiment, supporting the idea that acute AhR activation and induction of FGF21 is protective. ${ }^{54}$ Humans with metabolic illness such as diabetes often have FGF21 resistance, ${ }^{56}$ suggesting that $\mathrm{FGF} 21$ protection against metabolic dysregulation works only for acute insults and is not effective in long-term exposure. Transgenic mice with constitutively active AhR specific to the liver develop fatty liver, but not obesity or diabetes, when placed on HFD; knockdown of 
FGF21 in these AhR mice caused them to respond to HFD in the same way as their wild-type counterparts. ${ }^{57}$ In summary, both human and animal studies show a strong correlation between AhR activity and metabolic illness; the exact mechanisms behind this effect are still incompletely understood but may involve FGF21 and PPAR's working through improved glucose uptake and improved lipid and energy metabolism.

\section{Liver energy metabolism}

AhR activation affects systemic energy homeostasis through perturbations of glucose and lipid metabolism..$^{22,23} \mathrm{AhR}$ activation often disrupts hepatic glucose and lipid metabolism producing disease, ${ }^{54,56-63}$ while inhibition of AhR is protective for metabolic illnesses. ${ }^{28,41,55}$ Beneficial effects of AhR activity on liver glucose and lipid metabolism have also been shown, ${ }^{41,42,64}$ demonstrating the need to examine each experimental design closely. Effects of species, strain, sex and age of animals are likely to be important. ${ }^{65-67}$

AhR activation by dietary intake can lead to fatty liver. Six-week-old male C57BL/6 mice were fed a high methionine ( $2 \%$ methionine) diet for 1 and 2 months to induce hyperhomocysteinemia. They developed elevated levels of the fatty acid transport protein CD36, as well as fatty liver; both the increase in CD36 and the fatty liver were blocked by treatment with $\mathrm{CH} 22319$, an AhR antagonist, in drinking water at $10 \mathrm{mg} / \mathrm{kg} /$ day showing that the effect was AhR dependent. ${ }^{58}$

Environmental factors affecting metabolic illness include both dietary intake and obesogenic POPs. To study this interaction, male C57BL/6 mice (age unspecified) were fed a low-fat diet (LFD) containing 20\% of total calories as the unsaturated fatty acid linoleic acid or HFD containing $40 \%$ of total calories from linoleic acid for 4 months. After 2 months of the diet, they were intraperitoneally injected with polychlorinated biphenyls-77 (PCB77) $(170 \mu \mathrm{mol} / \mathrm{kg})$ or vehicle every 2 weeks for the remaining 2 months. Animals fed with the HFD had larger livers than those fed with LFD. The mice injected with PCB77 had even larger livers. DNA microarray analysis of liver tissue showed alterations in many genes related to fatty acid, triglyceride and cholesterol metabolism when mice were fed HFD, and PCBB77 had an interactive effect with diet. $^{59}$

Conclusive demonstration that the environmental factors of diet and obesogenic POPs work together to produce liver failure is provided by a recent study designed to mimic high levels of human exposure to TCDD. Seven-week-old male C57BL/6J mice were fed with LFD (10\% fat) or HFD ( $45 \%$ fat) for 14 weeks. After 8 weeks, mice received either vehicle injections or weekly $5 \mu \mathrm{g} / \mathrm{kg}$ TCDD injections for the final 6 weeks. This dosing strategy produced blood levels of TCDD in the mice similar to those found in humans following industrial accidents with TCDD exposure. The mice fed a HFD and treated with weekly TCDD demonstrated more fatty liver and fatty acid dysregulation than any of the other groups, demonstrating a synergistic effect of HFD and TCDD. ${ }^{60}$

To more specifically determine if the effects of obesogenic POPs act through AhR, wild-type and AhR knockout (AhRKO) animals (Bradfield strain) were treated with 2,3,7,8-tetrachlorodibenzofuran (TCDF) or vehicle. Wildtype 6-week-old male $\mathrm{C} 57 \mathrm{BL} / 6 \mathrm{~J}$ mice were fed dough pills with TCDF or vehicle for 5 days resulting in a total TCDF dose of $5 \mu \mathrm{g} / \mathrm{kg}$. AhRKO mice were treated the same, except that the total dose of TCDF was $24 \mu \mathrm{g} / \mathrm{kg}$ given over 5 days. Neither group demonstrated obvious liver problems; on pathological examination, mild liver dysfunction was seen in wild-type TCDF-treated animals. Metabolomics analysis of liver and serum showed that TCDF treatment in wild-type mice caused disruption of hepatic lipogenesis, as well as altered glucose, fatty acid and amino acid metabolism. There was no effect on AhRKO mice who could not process TCDF through the AhR. ${ }^{49}$

By contrast, one study using liver-specific knockdown of AhR demonstrated that AhR activity was protective against hepatotoxicity from HFD. Liver-specific knockout mice were prepared from $A h R^{f f o x f o x}$ and C57BL/6J mice with Cre recombinase gene. The final animals had knockout of $\mathrm{AhR}$ in liver only. In wild-type mice, HFD induced the expression of suppressor cytokines signal 3 (Socs3), which decreases inflammation and protects against HFD-induced obesity. Specific deletion of AhR in the liver inhibited the expression of Socs 3 leading to increased susceptibility to HFD-induced hepatotoxicity. AhR activation promotes Socs 3 expression suggesting that Socs 3 is the target of AhR activation. ${ }^{64}$

Several studies have shown that endogenous AhR suppresses transcription of genes required for cholesterol and fatty acid synthesis through a DRE-independent mechanism. Female C57BL/6J mice aged 10-12 weeks expressing total body AhRs with low or high binding affinity for ligand were examined. Mice with low-affinity AhRs (effectively AhR null mice) had higher transcription levels of enzymes required for fatty acid and cholesterol synthesis than mice of an identical genetic background except that they expressed high-affinity AhRs, indicating that endogenous AhR suppresses fatty acid and cholesterol synthesis. In addition, female C57BL/6J mice aged 10-12 weeks with a liver-specific AhR mutant that cannot bind DRE were injected with the AhR agonist, $\beta$-naphthoflavone. Both the wild-type AhR and the mutant 
inactive DRE binding AhR demonstrated decreased synthesis of fatty acids and cholesterol compared to AhR null mice. There was no difference between mice that effectively bound to DRE and those that did not, demonstrating that DRE binding is not necessary for the action of AhR in regulating enzymes responsible for fatty acid and cholesterol synthesis. ${ }^{41,42}$ These studies indicate that environmental factors such as diet and pollutants act together to affect liver function.

\section{Adipose tissue and lipid metabolism}

Lipophilic obesogenic POPs accumulate in fat-rich tissues and are resistant to metabolism. ${ }^{61}$ Thus, it is not surprising that adipose tissue would be a primary target mediating the effects of POPs on metabolism through AhR. Although once considered simply a storage organ for excess nutrients, white adipose tissue is now recognized as a critical endocrine regulator of systemic metabolism. Both obesity and lipodystrophies cause insulin resistance, highlighting the importance of proper adipose tissue mass and function in systemic metabolism. ${ }^{62,63,68}$ Adipose tissue regulates food intake, contributes to systemic insulin sensitivity and controls serum lipid levels.

Adipose tissue expansion through the formation of new adipocytes (adipogenesis) promotes insulin sensitivity in the face of obesity. By contrast, adipocyte cell expansion (hypertrophy) leads to lipid overloading and aberrant adipokine production, which likely produces systemic insulin resistance ${ }^{69-71}$ Activation of AhR within adipose tissue generally inhibits adipogenesis, attenuating the production of new adult adipocytes, and impedes lipolysis, reducing the release of free fatty acids into the blood. AhR regulates cell proliferation and differentiation of mesenchymal stem cells and preadipocytes within adipose tissue. AhR activation by TCDD treatment suppresses differentiation of preadipocytes; depletion of nuclear AhR restores preadipocyte differentiation. ${ }^{72,73} \mathrm{AhR}$ protein is downregulated when preadipocytes differentiate into mature adipocytes.

Together, this evidence suggests that AhR activity negatively regulates adipogenesis, increasing susceptibility to metabolic illnesses. These effects are likely mediated through downregulation of PPAR $\gamma$ and stearoyl-CoA desaturase type $1^{51}$ and higher activity of p42/p44 MAP kinase. AhR stabilizes activity of the retinoblastoma family member, p107, which binds to PPAR $\gamma$. Ultimately, both MAPK kinase activity and p107 suppress PPAR $\gamma$ activity, thereby inhibiting adipogenesis. Activation of PPAR $\gamma$ with troglitazone, ciglitazone and indomethacin overcomes the inhibition of differentiation imposed by overexpression of AhR. ${ }^{74,75}$
AhR has different effects on several cellular activities to inhibit adipogenesis. TCDD works synergistically with extracellular signal-regulated kinase to decrease PPAR $\gamma$ activity. The AhR antagonist 3V-methoxy-4V-nitroflavone blocks TCDD-induced Cyp1B1 activation and eliminates TCDD-induced PPAR $\gamma$ inhibition. ${ }^{76,77}$ In the C3H10T1/2 (pluripotent mouse mesenchymal stem cell) culture line, TCDD blocks the differentiation effects of inducers; microarray studies suggest that this inhibition of differentiation into adipocytes may be mediated through TCDD effects on cell adhesion-linked signaling pathways. ${ }^{78}$ TCDD inhibits differentiation of mouse embryonic fibroblasts into adipocytes by increasing levels of known regulators of cellular differentiation, CCAAT/enhancer-binding protein $(\mathrm{C} / \mathrm{EBP} \beta$ and $\mathrm{C} / \mathrm{EBP} \delta$ ), in a tyrosine kinase c-Src-dependent manner. ${ }^{79}$ AhR cooperates with nuclear factor (erythroid-derived 2)-like 2 (NRF2) to inhibit adipogenesis, since activation or overexpression of AhR in NRF2-deficient cells decreases adipogenesis. $^{80}$

In toxicological studies, downstream effects of AhR activation can sometimes differ depending on the nature of the AhR ligand. However, suppression of adipogenesis by AhR activation occurs in response to a variety of AhR ligands. Mycelial extract of Cordyceps militaris and benzo[a]pyrene (BaP) activate AhR and inhibit adipogenesis in cultured mouse 3T3L1 cells, which have a fibroblast morphology, but can differentiate into an adipocyte phenotype. AhR inhibition of adipogenesis in 3T3L1 cells occurs through decreasing PPAR $\gamma$ and $\mathrm{C} / \mathrm{EBP} \alpha$. Dominant-negative inhibition of AhR blocks these effects. ${ }^{75} \mathrm{H}$ Mycelial extract of $C$. militaris inhibits mammalian target of rapamycin complex 1 signaling pathway via inhibition of AKT leading to a decrease in the expression of $C / E B P \beta$ and $P P A R \gamma \cdot{ }^{81,82}$ Thus, the inhibitory effects of $\mathrm{AhR}$ on adipogenesis are multifactorial and complex.

In a cell line derived from human subcutaneous fat tissue of a non-diabetic donor, obesogenic POPs decreased adipogenesis. These effects were blocked by the AhR antagonist $\mathrm{CH} 223191 .^{83} \mathrm{BaP}$ inhibits adipogenesis in mesenchymal stem cells derived from human bone marrow by decreasing the expression of fatty acid binding protein 4 and glyceraldehyde-3-phosphate dehydrogenase (GAPDH); the AhR antagonist $\alpha$-naphthoflavone blocks these effects. ${ }^{84}$ The AhR agonist indole-3-carbinol decreases lipid accumulation and expression of $N R F 2$, hormone-sensitive lipase (HSL) and GAPDH in mature adipocytes. ${ }^{85}$ Taken together, these data demonstrate the importance of AhR activation by a wide variety of agonists in regulating adipogenesis. Inhibition of 
adipogenesis by AhR activation decreases the overall numbers of adipocytes available for storing fat.

AhR also affects the lipolysis function of mature adipocytes. Lipolysis functions as an important regulator of systemic energy homeostasis by providing the body with free fatty acids during fasting and exercise. Defective lipolysis disrupts systemic metabolic processes. ${ }^{86,87}$ Adipose triglyceride lipase (ATGL), HSL and monoglyceride lipase (MGL) are key enzymes that regulate this process. ATGL initially hydrolyzes triacylglycerols to produce diacylglycerols (DAGs) and free fatty acids. HSL hydrolyzes DAGs to produce monoacylglycerols (MAGs). Finally, MAGs are broken down to glycerol and non-esterified fatty acids by MGL. ${ }^{88-90}$

Activation of AhR by the agonist $\beta$-naphthoflavone inhibits expression of lipolysis genes in differentiated 3T3-L1 adipocyte cultures (Khazaal and Tischkau, unpublished results) and suppresses lipolysis. BaP suppresses $\beta$-adrenoceptor agonist-induced lipolysis in adipose primary explants from mice and humans. In male C57BL/6J mice, weighing 20-22 g (11 weeks), chronic injection of $\mathrm{BaP}(0.5 \mathrm{mg} / \mathrm{kg}$ every 2 days $)$ for 15 days increased body weight and fat mass, although the food intake was similar. ${ }^{91}$ However, Hsu et al found that TCDD has no effects on lipolysis in 3T3-L1 cells. This may be because they used the wrong time point. They measured glycerol content in media of fully differentiated cells treated with TCDD for 3 days or shortly after addition of TCDD. ${ }^{75}$

AhR activation may also increase inflammation in adipose tissue. Administration of obesogenic POPs increases tumor necrosis factor- $\alpha$ (TNF $\alpha$ ) expression in white adipose tissue, which may lead to impaired glucose tolerance in lean and in obese mice. ${ }^{92}$ Selective ablation of AhR in adipose tissue abolishes the negative effects of POPs on obesity, inflammation and glucose intolerance. ${ }^{93}$ TCDD activation of adipocytes leads to insulin resistance through $\mathrm{TNF} \alpha{ }^{94}$ Collectively, these data demonstrate that lipophilic adipogenic POPs accumulate in adipose tissue where they activate AhR. Activated AhR in adipose tissue inhibits adipogenesis, thereby reducing the overall number of fat cells available to store lipids. AhR activation inhibits lipolysis, reducing the ability of adipocytes to break down stored triglycerides into free fatty acids. Finally, AhR activation in adipocytes promotes an inflammatory response in adipose tissue, which contributes to the development of insulin resistance. When combined with long-term exposure to excess energy (HFD), the reduced number of fat cells with impaired ability to breakdown lipids may become over-burdened with lipid, which may subsequently promote local inflammation, leading to insulin resistance (Figure 2).

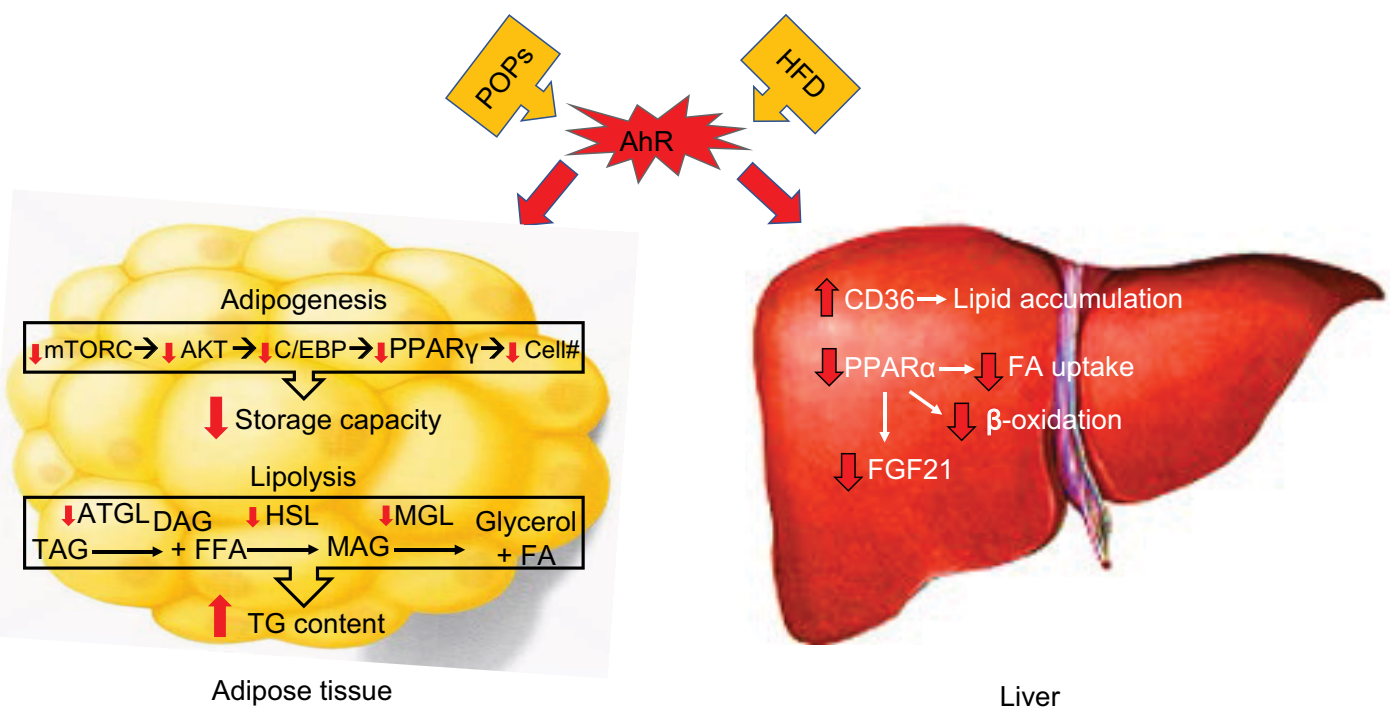

Figure 2 AhR regulates body metabolism through actions in the liver and adipose tissue.

Notes: AhR activation by POPs and/or high-fat diet directly targets certain genes controlling glucose and lipid metabolism in the liver and adipose tissue, thereby directly contributing to the development of metabolic disorders. In adipose tissue, AhR activation targets adipogenesis and lipolysis, acting to inhibit both processes. In adipose tissue, AhR suppresses mTORC, which decreases AKT activity and inhibits PPAR $\gamma$ levels, ultimately leading to decreased differentiation of pre-adipocytes. The reduction in adipocyte numbers provides fewer adult adipocytes for capturing lipids. Under HFD conditions, adipocytes become hypertrophied and ultimately overwhelmed; lipid then accumulates in other organs and adipose tissue becomes inflamed. In the liver, AhR activation promotes CD36, which enhances lipid uptake by the liver. AhR activation also suppresses PPAR $\alpha$, leading to decreased $\beta$-oxidation and FA metabolism. Finally, AhR may regulate FGF2I, which has a role in regulation of systemic metabolism through effects on adipose tissue function.

Abbreviations: AhR, aryl hydrocarbon receptor; POPs, persistent organic pollutants; mTORC, mammalian target of rapamycin complex; PPAR, peroxisome proliferatoractivated receptor; HFD, high-fat diet; FA, fatty acid; FGF2I, fibroblast growth factor 2I; C/EBP, CCAAT/enhancer-binding protein; ATGL, adipose triglyceride lipase; DAG, diacylglycerol; HSL, hormone-sensitive lipase; MAG, monoacylglycerol; MGL, monoglyceride lipase; TG, triglycerides; FFA, free fatty acids; TAG, triacyl glycerol. 


\section{AhR, circadian rhythms and metabolism}

Alteration of circadian rhythm, specifically inhibition of the clock genes Period 1 (PER1) ${ }^{31}$ and Rev-erba (Sun and Tischkau, unpublished results), may contribute to metabolic dysfunction by AhR activation. Controlled by a master clock in the hypothalamic suprachiasmatic nucleus (SCN), the circadian timing system has emerged as an important regulator of systemic energy metabolism. ${ }^{95}$ The $\mathrm{SCN}$ provides sympathetic and parasympathetic input to the liver and pancreas ${ }^{96}$ to regulate hepatic glucose production and insulin release, respectively. ${ }^{97}$ Glucocorticoids and melatonin are hormonal signals that also contribute to clock regulation of systemic metabolism. ${ }^{98-101}$

At the cellular level, circadian clock genes regulate energy balance and metabolism. Mutations or deletion of certain clock genes, including Circadian Locomotor Output Cycles Kaput (CLOCK), PERs and cryptochromes, promote obesity, elevated blood glucose and insulin resistance. ${ }^{102-105}$ In humans, PER 2 mutations are associated with elevated fasting blood glucose, supporting the link between clock genes and metabolic syndrome. ${ }^{106} \mathrm{By}$ contrast, liver-specific deletion of the clock gene brain muscle ARNT-like protein 1 (BMAL1) produces hypoglycemia, enhanced glucose clearance and loss of rhythmic expression of glucose regulatory genes. ${ }^{107}$

Disrupted circadian rhythms, as commonly occur in human shift workers, are associated with glucose dysregulation, obesity and metabolic syndrome. ${ }^{108,109}$ Experimental shift work models support the effects of circadian desynchrony on metabolic disruption. ${ }^{110,111}$ Alteration in light/dark cycles in rodent studies suggests that internal desynchrony results from the SCN's rapid shift to align with light/dark cycles, but peripheral clocks becoming uncoupled due to increased food intake during the inactive period. ${ }^{111,112}$ This type of internal desynchrony is consistent with the effects of AhR activation on circadian clock function, thereby providing an interesting piece of the mechanism by which both AhR and the clock may interact.

AhR and its partner ARNT as well as core circadian clock genes, CLOCK and BMAL1, are all members of the PAS domain-containing family of transcriptional regulators. ${ }^{113}$ Reciprocal crosstalk between AhR signaling and circadian rhythms has been established. ${ }^{114}$ AhR expression is controlled by the circadian clock, likely through $C L O C K /$ BMAL1 binding to E boxes in the AhR promoter. ${ }^{15} \mathrm{AhR}$, ARNT and a number of drug-processing genes are rhythmically expressed; ${ }^{116-119}$ AhR rhythmicity is abolished in CLOCK-mutant mice. ${ }^{120} \mathrm{AhR}, \mathrm{CYP} 1 \mathrm{~A} 1$ and CYP1B1 levels are increased, yet expression is arrhythmic in PER1 and PER2 mutant mice. ${ }^{121-123}$ Conversely, activation of AhR by TCDD leads to alterations in PER1, PER2 and BMAL1 expression and reduces the ability of the circadian clock to respond to changes in the light/dark cycle. ${ }^{14,119,121-128}$ Moreover, AhR can directly interact with $B M A L 1$ to attenuate PER1 expression due to decreased binding of CLOCK-BMAL1 to E-box of PER1 promoter. ${ }^{129}$ PERl expression and rhythm is higher in AhRKO mice than wild-type mice suggesting that these mice had higher response to the light. ${ }^{31}$

Interestingly, like the shift work studies, chronic activation of AhR alters clock function in peripheral metabolically important tissues, while the master clock in the SCN remains aligned with the light/dark cycle. ${ }^{129}$ Systemic activation of AhR by treatment with TCDD suppresses the amplitude and delays the peak of PERI expression in the liver. Activated AhR can interact with $B M A L 1$ to suppress E-box derived transcription of the PER1 gene. PER1 rhythms in the SCN of these same animals were relatively unaffected by TCDD. ${ }^{31}$ It is likely that the PERI rhythm was retained in the SCN due to reduced expression of AhR in this tissue and the overriding effects of light in maintaining strong rhythms in the primary clock. However, a shift of liver rhythms creates an internal desynchrony that may underlie the development of metabolic syndrome that is common to both shift work and chronic AhR activation.

Studies in AhR-deficient mice support the cooperation between AhR signaling and the clock in regulation of metabolism. AhR activation suppresses rhythmicity in wildtype AhR-sensitive strains of mice. ${ }^{129}$ Mice with germline deletion of one or both $A h R$ alleles have increased circadian rhythm amplitude and increased responsiveness to changes in the light/dark cycle indicative of enhanced robustness of their circadian clock. ${ }^{31,125,126,129-131}$ Whereas a HFD usually dampens circadian rhythms in metabolically important tissues, AhR-deficient animals retain robust circadian rhythmicity under HFD conditions. ${ }^{30}$ Although these studies have not established cause and effect, they support the hypothesis that robust rhythms are important for metabolic health and that AhR interacts with the clock to deregulate energy metabolism.

\section{Conclusion}

AhR activation may contribute to obesity and downstream metabolic disorders. AhR regulates expression of myriad genes, ${ }^{132}$ including many associated with obesity, lipid metabolism and inflammation. ${ }^{43,44}$ Understanding AhRdependent mechanisms that contribute to metabolic homeostasis will provide a more holistic understanding regarding 


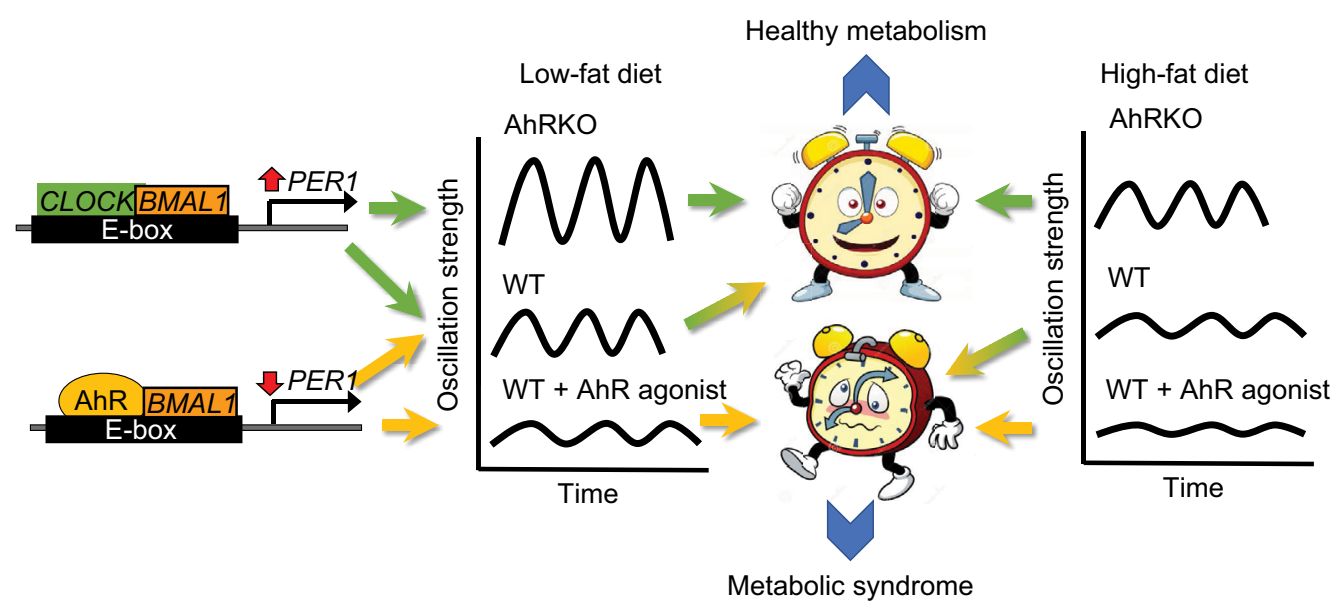

Figure $3 \mathrm{~A}$ healthy circadian clock maintains synchronization of central and peripheral rhythms with the external environment resulting in metabolic homeostasis. AhR can compete with CLOCK to form heterodimers with the clock gene, BMALI. Although CLOCK/BMALI act as activators on the E-box of the PER promoter, AhR/BMALI suppresses activity at the E-box. Thus, removal of AhR enhances CLOCKIBMALI activity and increases the amplitude of circadian oscillations. When AhR is present, rhythm amplitude is slightly dampened by endogenous activation of AhR. In the presence of AhR agonists, AhR/BMALI activity dominates at the E-box, thereby further dampening the rhythm. HFD can also dampen rhythms, which are strongly associated with metabolic dysfunction. Thus, activation of AhR and HFD interacts to compound the detrimental effects on metabolism. AhR depletion protects against the detrimental effects of HFD by promoting rhythm amplitude and maintaining a healthy clock.

Abbreviations: AhR, aryl hydrocarbon receptor; CLOCK, Circadian Locomotor Output Cycles Kaput; BMALI, brain muscle ARNT-like protein I; HFD, high-fat diet; AhRKO, AhR knockout; WT, wild type.

environmental factors that contribute to worldwide pandemics in obesity and metabolic dysfunction. Therapies to address these important global problems are not as simple as fixing diet and encouraging exercise. This review highlights how complex environmental signals, including light/dark cycles and chemical exposure contribute to metabolic health. Altered circadian rhythms, through changes in light/dark cycles, HFD and/or exposure to AhR-activating chemicals, promote metabolic dysfunction. Inhibition of AhR or its downstream signals may provide new targets for combatting these problems. AhR inhibition or silencing protects from the metabolic consequences of rhythm disruption (Figure 3). ${ }^{30,44,130}$

Interestingly, adipose tissue has emerged as an important site regulating whole-body energy metabolism. Many chemicals that activate AhR are lipophilic and aggregate within adipose tissue. However, a recent study demonstrated that altered rhythms in one tissue can lead to disrupted function of other tissues. ${ }^{133}$ AhR is highly expressed in adipose tissue and appears to regulate important adipocyte functions, including adipogenesis and lipolysis. As lipolysis is highly controlled by the circadian clock, future studies will examine interactions of AhR with the clock during this physiological process. A better understanding of clock/AhR interactions may provide novel therapeutic approaches to combat obesity and metabolic syndrome.

\section{Acknowledgment}

Funding was provided by NIH ES017774 to SAT.

\section{Disclosure}

The authors report no conflicts of interest in this work.

\section{References}

1. Cai L, Lubitz J, Flegal KM, Pamuk ER. The predicted effects of chronic obesity in middle age on medicare costs and mortality. Med Care. 2010;48(6):510-517.

2. Olshansky SJ, Passaro DJ, Hershow RC, et al. A potential decline in life expectancy in the United States in the 21st century. N Engl J Med. 2005;352(11):1138-1145.

3. Ogden CL, Carroll MD, Fryar CD, Flegal KM. Prevalence of obesity among adults and youth: United States, 2011-2014. NCHS Data Brief. 2015;(219):1-8.

4. Ogden CL, Carroll MD, Kit BK, Flegal KM. Prevalence of childhood and adult obesity in the United States, 2011-2012. JAMA. 2014;311(8): 806-814.

5. Finkelstein EA, Trogdon JG, Cohen JW, Dietz W. Annual medical spending attributable to obesity: payer-and service-specific estimates. Health Aff (Millwood). 2009;28(5):w822-w831.

6. Klimentidis YC, Beasley TM, Lin HY, et al. Canaries in the coal mine: a cross-species analysis of the plurality of obesity epidemics. Proc Biol Sci. 2011;278(1712):1626-1632.

7. Le Magueresse-Battistoni B, Labaronne E, Vidal H, Naville D. Endocrine disrupting chemicals in mixture and obesity, diabetes and related metabolic disorders. World J Biol Chem. 2017;8(2):108-119.

8. Diamanti-Kandarakis E, Bourguignon JP, Giudice LC, et al. Endocrinedisrupting chemicals: an Endocrine Society scientific statement. Endocr Rev. 2009;30(4):293-342.

9. Grun F, Blumberg B. Environmental obesogens: organotins and endocrine disruption via nuclear receptor signaling. Endocrinology. 2006;147(6 Suppl):S50-S55.

10. De Tata V. Association of dioxin and other persistent organic pollutants (POPs) with diabetes: epidemiological evidence and new mechanisms of beta cell dysfunction. Int J Mol Sci. 2014;15(5):7787-7811.

11. Gasull M, Pumarega J, Tellez-Plaza M, et al. Blood concentrations of persistent organic pollutants and prediabetes and diabetes in the general population of Catalonia. Environ Sci Technol. 2012;46(14):7799-7810. 
12. Honda T, Pun VC, Manjourides J, Suh H. Associations between longterm exposure to air pollution, glycosylated hemoglobin and diabetes. Int J Hyg Environ Health. 2017;220(7):1124-1132.

13. Henriquez-Hernandez LA, Luzardo OP, Valeron PF, et al. Persistent organic pollutants and risk of diabetes and obesity on healthy adults: results from a cross-sectional study in Spain. Sci Total Environ. 2017;607-608:1096-1102.

14. Oken E, Levitan EB, Gillman MW. Maternal smoking during pregnancy and child overweight: systematic review and meta-analysis. Int J Obes (Lond). 2008;32(2):201-210.

15. Wu XM, Basu R, Malig B, et al. Association between gaseous air pollutants and inflammatory, hemostatic and lipid markers in a cohort of midlife women. Environ Int. 2017;107:131-139.

16. Hsieh $\mathrm{S}$, Leaderer BP, Feldstein AE, et al. Traffic-related air pollution associations with cytokeratin-18, a marker of hepatocellular apoptosis, in an overweight and obese paediatric population. Pediatr Obes. Epub 2017 Jul 20.

17. Airaksinen R, Rantakokko P, Eriksson JG, Blomstedt P, Kajantie E, Kiviranta H. Association between type 2 diabetes and exposure to persistent organic pollutants. Diabetes Care. 2011;34(9):1972-1979.

18. Alonso-Magdalena P, Quesada I, Nadal A. Endocrine disruptors in the etiology of type 2 diabetes mellitus. Nat Rev Endocrinol. 2011;7: 346-353.

19. Ha MH, Lee DH, Jacobs DR. Association between serum concentrations of persistent organic pollutants and self-reported cardiovascular disease prevalence: results from the National Health and Nutrition Examination Survey, 1999-2002. Environ Health Perspect. 2007;115(8):1204-1209.

20. Uemura H, Arisawa K, Hiyoshi M, et al. Prevalence of metabolic syndrome associated with body burden levels of dioxin and related compounds among Japan's general population. Environ Health Perspect. 2009;117(4):568-573.

21. Roh E, Kwak SH, Jung HS, et al. Serum aryl hydrocarbon receptor ligand activity is associated with insulin resistance and resulting type 2 diabetes. Acta Diabetol. 2015;52(3):489-495.

22. Denison MS, Fisher JM, Whitlock JP. The DNA recognition site for the dioxin-Ah receptor complex. Nucleotide sequence and functional analysis. J Biol Chem. 1988;263(33):17221-17224.

23. Denison MS, Nagy SR. Activation of the aryl hydrocarbon receptor by structurally diverse exogenous and endogenous chemicals. Annu Rev Pharmacol Toxicol. 2003;43:309-334.

24. Gasiewicz TA, Kende AS, Rucci G, Whitney B, Willey JJ. Analysis of structural requirements for Ah receptor antagonist activity: ellipticines, flavones, and related compounds. Biochem Pharmacol. 1996;52(11):1787-1803.

25. Poland A, Knutson JC. 2,3,7,8-tetrachlorodibenzo-p-dioxin and related halogenated aromatic hydrocarbons: examination of the mechanism of toxicity. Annu Rev Pharmacol Toxicol. 1982;22:517-554.

26. Gu YZ, Hogenesch JB, Bradfield CA. The PAS superfamily: sensors of environmental and developmental signals. Annu Rev Pharmacol Toxicol. 2000;40:519-561.

27. McGuire J, Okamoto K, Whitelaw ML, Tanaka H, Poellinger L. Definition of a dioxin receptor mutant that is a constitutive activator of transcription: delineation of overlapping repression and ligand binding functions within the PAS domain. J Biol Chem. 2001;276(45):41841-41849.

28. Reisz-Porszasz S, Probst MR, Fukunaga BN, Hankinson O. Identification of functional domains of the aryl hydrocarbon receptor nuclear translocator protein (ARNT). Mol Cell Biol. 1994;14(9):6075-6086.

29. Stockinger B, Di Meglio P, Gialitakis M, Duarte JH. The aryl hydrocarbon receptor: multitasking in the immune system. Annu Rev Immunol. 2014;32:403-432.

30. Xu CX, Wang C, Zhang ZM, et al. Aryl hydrocarbon receptor deficiency protects mice from diet-induced adiposity and metabolic disorders through increased energy expenditure. Int $J$ Obes (Lond). 2015;39(8):1300-1309.
31. Xu CX, Krager SL, Liao DF, Tischkau SA. Disruption of CLOCKBMAL1 transcriptional activity is responsible for aryl hydrocarbon receptor-mediated regulation of Period1 gene. Toxicol Sci. 2010;115(1): 98-108.

32. Pocar P, Fischer B, Klonisch T, Hombach-Klonisch S. Molecular interactions of the aryl hydrocarbon receptor and its biological and toxicological relevance for reproduction. Reproduction. 2005;129(4): 379-389.

33. Marlowe JL, Puga A. Aryl hydrocarbon receptor, cell cycle regulation, toxicity, and tumorigenesis. J Cell Biochem. 2005;96(6):1174-1184.

34. Ge NL, Elferink CJ. A direct interaction between the aryl hydrocarbon receptor and retinoblastoma protein. Linking dioxin signaling to the cell cycle. J Biol Chem. 1998;273(35):22708-22713.

35. Frericks M, Meissner M, Esser C. Microarray analysis of the AHR system: tissue-specific flexibility in signal and target genes. Toxicol Appl Pharmacol. 2007;220(3):320-332.

36. Perdew GH. Association of the Ah receptor with the $90-\mathrm{kDa}$ heat shock protein. J Biol Chem. 1988;263(27):13802-13805.

37. Petrulis JR, Bunce NJ. Competitive behavior in the interactive toxicology of halogenated aromatic compounds, J Biochem Mol Toxicol. 2000;14(2):73-81.

38. Petrulis JR, Hord NG, Perdew GH. Subcellular localization of the aryl hydrocarbon receptor is modulated by the immunophilin homolog hepatitis B virus X-associated protein 2. J Biol Chem. 2000;275(48): 37448-37453.

39. Ikuta T, Eguchi H, Tachibana T, Yoneda Y, Kawajiri K. Nuclear localization and export signals of the human aryl hydrocarbon receptor. J Biol Chem. 1998;273(5):2895-2904.

40. Ko HP, Okino ST, Ma Q, Whitlock JP Jr. Dioxin-induced CYP1A1 transcription in vivo: the aromatic hydrocarbon receptor mediates transactivation, enhancer-promoter communication, and changes in chromatin structure. Mol Cell Biol. 1996;16(1):430-436.

41. Tanos R, Murray IA, Smith PB, Patterson A, Perdew GH. Role of the Ah receptor in homeostatic control of fatty acid synthesis in the liver. Toxicol Sci. 2012;129(2):372-379.

42. Tanos R, Patel RD, Murray IA, Smith PB, Patterson AD, Perdew GH. Aryl hydrocarbon receptor regulates the cholesterol biosynthetic pathway in a dioxin response element-independent manner. Hepatology. 2012;55(6):1994-2004.

43. Kerley-Hamilton JS, Trask HW, Ridley CJ, et al. Obesity is mediated by differential aryl hydrocarbon receptor signaling in mice fed a Western diet. Environ Health Perspect. 2012;120(9):1252-1259.

44. Wang C, Xu CX, Krager SL, Bottum KM, Liao DF, Tischkau SA. Aryl hydrocarbon receptor deficiency enhances insulin sensitivity and reduces PPAR-alpha pathway activity in mice. Environ Health Perspect. 2011;119(12):1739-1744.

45. Calvert GM, Sweeney MH, Deddens J, Wall DK. Evaluation of diabetes mellitus, serum glucose, and thyroid function among United States workers exposed to 2,3,7,8-tetrachlorodibenzo-p-dioxin. Occup Environ Med. 1999;56(4):270-276.

46. Cranmer M, Louie S, Kennedy RH, Kern PA, Fonseca VA. Exposure to 2,3,7,8-tetrachlorodibenzo-p-dioxin (TCDD) is associated with hyperinsulinemia and insulin resistance. Toxicol Sci. 2000;56(2):431-436.

47. Bertazzi PA, Bernucci I, Brambilla G, Consonni D, Pesatori AC. The Seveso studies on early and long-term effects of dioxin exposure: a review. Environ Health Perspect. 1998;106 (Suppl 2):625-633.

48. Kern PA, Said S, Jackson WG Jr, Michalek JE. Insulin sensitivity following agent orange exposure in Vietnam veterans with high blood levels of 2,3,7,8-tetrachlorodibenzo-p-dioxin. J Clin Endocrinol Metab. 2004;89(9):4665-4672.

49. Zhang L, Hatzakis E, Nichols RG, et al. Metabolomics reveals that aryl hydrocarbon receptor activation by environmental chemicals induces systemic metabolic dysfunction in mice. Environ Sci Technol. 2015;49(13):8067-8077.

50. Remillard RB, Bunce NJ. Linking dioxins to diabetes: epidemiology and biologic plausibility. Environ Health Perspect. 2002;110(9):853-858. 
51. Alexander DL, Ganem LG, Fernandez-Salguero P, Gonzalez F, Jefcoate CR. Aryl-hydrocarbon receptor is an inhibitory regulator of lipid synthesis and of commitment to adipogenesis. J Cell Sci. 1998;111 (Pt 22):3311-3322.

52. Fernandez-Salguero PM, Hilbert DM, Rudikoff S, Ward JM, Gonzalez FJ. Aryl-hydrocarbon receptor-deficient mice are resistant to 2,3,7,8-tetrachlorodibenzo-p-dioxin-induced toxicity. Toxicol Appl Pharmacol. 1996;140(1):173-179.

53. Iglesias P, Selgas R, Romero S, Díez JJ. Biological role, clinical significance, and therapeutic possibilities of the recently discovered metabolic hormone fibroblastic growth factor 21. Eur J Endocrinol. 2012;167(3):301-309.

54. Cheng X, Vispute SG, Liu J, Cheng C, Kharitonenkov A, Klaassen CD. Fibroblast growth factor (Fgf) 21 is a novel target gene of the aryl hydrocarbon receptor (AhR). Toxicol Appl Pharmacol. 2014;278(1): 65-71.

55. Girer NG, Murray IA, Omiecinski CJ, Perdew GH. Hepatic aryl hydrocarbon receptor attenuates fibroblast growth factor 21 expression. J Biol Chem. 2016;291(29):15378-15387.

56. So WY, Cheng Q, Xu A, Lam KS, Leung PS. Loss of fibroblast growth factor 21 action induces insulin resistance, pancreatic islet hyperplasia and dysfunction in mice. Cell Death Dis. 2015;6:e1707.

57. Lu P, Yan J, Liu K, et al. Activation of aryl hydrocarbon receptor dissociates fatty liver from insulin resistance by inducing fibroblast growth factor 21. Hepatology. 2015;61(6):1908-1919.

58. Yao L, Wang C, Zhang X, et al. Hyperhomocysteinemia activates the aryl hydrocarbon receptor/CD36 pathway to promote hepatic steatosis in mice. Hepatology. 2016;64(1):92-105.

59. Arzuaga X, Ren N, Stromberg A, et al. Induction of gene pattern changes associated with dysfunctional lipid metabolism induced by dietary fat and exposure to a persistent organic pollutant. Toxicol Lett. 2009;189(2):96-101.

60. Duval C, Teixeira-Clerc F, Leblanc AF, et al. Chronic exposure to low doses of dioxin promotes liver fibrosis development in the C57BL/6 J diet-induced obesity mouse model. Environ Health Perspect. 2017;125(3):428-436.

61. Myre M, Imbeault P. Persistent organic pollutants meet adipose tissue hypoxia: does cross-talk contribute to inflammation during obesity? Obes Rev. 2014;15(1):19-28.

62. Mlinar B, Marc J. New insights into adipose tissue dysfunction in insulin resistance. Clin Chem Lab Med. 2011;49(12):1925-1935.

63. Guilherme A, Virbasius JV, Puri V, Czech MP. Adipocyte dysfunctions linking obesity to insulin resistance and type 2 diabetes. Nat Rev Mol Cell Biol. 2008;9(5):367-377.

64. Wada T, Sunaga H, Miyata K, Shirasaki H, Uchiyama Y, Shimba S. Aryl hydrocarbon receptor plays protective roles against high fat diet (HFD)-induced hepatic steatosis and the subsequent lipotoxicity via direct transcriptional regulation of Socs 3 gene expression. J Biol Chem. 2016;291(13):7004-7016.

65. Pohjanvirta R, Wong JM, Li W, Harper PA, Tuomisto J, Okey AB. Point mutation in intron sequence causes altered carboxyl-terminal structure in the aryl hydrocarbon receptor of the most 2,3,7,8-tetrachlorodibenzo-p-dioxin-resistant rat strain. Mol Pharmacol. 1998;54(1):86-93.

66. Pohjanvirta R, Viluksela M, Tuomisto JT, et al. Physicochemical differences in the AH receptors of the most TCDD-susceptible and the most TCDD-resistant rat strains. Toxicol Appl Pharmacol. 1999;155(1): 82-95.

67. Nault R, Kim S, Zacharewski TR. Comparison of TCDD-elicited genome-wide hepatic gene expression in Sprague-Dawley rats and C57BL/6 mice. Toxicol Appl Pharmacol. 2013;267(2):184-191.

68. Harwood HJ Jr. The adipocyte as an endocrine organ in the regulation of metabolic homeostasis. Neuropharmacology. 2012;63(1): $57-75$.

69. Virtue S, Vidal-Puig A. It's not how fat you are, it's what you do with it that counts. PLoS Biol. 2008;6(9):e237.
70. Medina-Gomez G, Gray S, Vidal-Puig A. Adipogenesis and lipotoxicity: role of peroxisome proliferator-activated receptor gamma (PPARgamma) and PPARgammacoactivator-1 (PGC1). Public Health Nutr. 2007;10(10A):1132-1137.

71. Hajer GR, van Haeften TW, Visseren FL. Adipose tissue dysfunction in obesity, diabetes, and vascular diseases. Eur Heart $J$. 2008;29(24):2959-2971.

72. Shimba S, Todoroki K, Aoyagi T, Tezuka M. Depletion of arylhydrocarbon receptor during adipose differentiation in 3T3-L1 cells. Biochem Biophys Res Commun. 1998;249(1):131-137.

73. Shimba S, Hayashi M, Ohno T, Tezuka M. Transcriptional regulation of the AhR gene during adipose differentiation. Biol Pharm Bull. 2003;26(9):1266-1271.

74. Shimba S, Wada T, Tezuka M. Arylhydrocarbon receptor (AhR) is involved in negative regulation of adipose differentiation in 3T3-L1 cells: AhR inhibits adipose differentiation independently of dioxin. J Cell Sci. 2001;114(Pt 15):2809-2817.

75. Hsu HF, Tsou TC, Chao HR, Kuo YT, Tsai FY, Yeh SC. Effects of 2,3,7,8-tetrachlorodibenzo-p-dioxin on adipogenic differentiation and insulin-induced glucose uptake in 3T3-L1 cells. J Hazard Mater. 2010;182(1-3):649-655.

76. Hanlon PR, Ganem LG, Cho YC, Yamamoto MY, Jefcoate CR. AhRand ERK-dependent pathways function synergistically to mediate 2,3,7,8-tetrachlorodibenzo-p-dioxin suppression of peroxisome proliferator-activated receptor-gamma1 expression and subsequent adipocyte differentiation. Toxicol Appl Pharmacol. 2003;189(1): 11-27.

77. Cimafranca MA, Hanlon PR, Jefcoate CR. TCDD administration after the pro-adipogenic differentiation stimulus inhibits PPARgamma through a MEK-dependent process but less effectively suppresses adipogenesis. Toxicol Appl Pharmacol. 2004;196(1):156-168.

78. Hanlon PR, Cimafranca MA, Liu X, Cho YC, Jefcoate CR. Microarray analysis of early adipogenesis in $\mathrm{C} 3 \mathrm{H} 10 \mathrm{~T} 1 / 2$ cells: cooperative inhibitory effects of growth factors and 2,3,7,8-tetrachlorodibenzo-p-dioxin. Toxicol Appl Pharmacol. 2005;207(1):39-58.

79. Vogel CF, Matsumura F. Interaction of 2,3,7,8-tetrachlorodibenzop-dioxin (TCDD) with induced adipocyte differentiation in mouse embryonic fibroblasts (MEFs) involves tyrosine kinase c-Src. Biochem Pharmacol. 2003;66(7):1231-1244.

80. Shin S, Wakabayashi N, Misra V, et al. NRF2 modulates aryl hydrocarbon receptor signaling: influence on adipogenesis. Mol Cell Biol. 2007;27(20):7188-7197.

81. Takahashi S, Tamai M, Nakajima S, et al. Blockade of adipocyte differentiation by cordycepin. Br J Pharmacol. 2012;167(3):561-575.

82. Shimada T, Hiramatsu N, Kasai A, et al. Suppression of adipocyte differentiation by Cordyceps militaris through activation of the aryl hydrocarbon receptor. Am J Physiol Endocrinol Metab. 2008;295(4): E859-E867.

83. Gadupudi G, Gourronc FA, Ludewig G, Robertson LW, Klingelhutz AJ. PCB126 inhibits adipogenesis of human preadipocytes. Toxicol In Vitro. 2015;29(1):132-141.

84. Podechard N, Fardel O, Corolleur M, Bernard M, Lecureur V. Inhibition of human mesenchymal stem cell-derived adipogenesis by the environmental contaminant benzo(a)pyrene. Toxicol In Vitro. 2009;23(6):1139-1144.

85. Wang ML, Lin SH, Hou YY, Chen YH. Suppression of lipid accumulation by indole-3-carbinol is associated with increased expression of the aryl hydrocarbon receptor and CYP1B1 proteins in adipocytes and with decreased adipocyte-stimulated endothelial tube formation. Int $J$ Mol Sci. 2016;17(8):1256.

86. Wang SP, Laurin N, Himms-Hagen J, et al. The adipose tissue phenotype of hormone-sensitive lipase deficiency in mice. Obes Res. 2001;9(2): 119-128.

87. Haemmerle G, Lass A, Zimmermann R, et al. Defective lipolysis and altered energy metabolism in mice lacking adipose triglyceride lipase. Science. 2006;312(5774):734-737. 
88. Lass A, Zimmermann R, Oberer M, Zechner R. Lipolysis - a highly regulated multi-enzyme complex mediates the catabolism of cellular fat stores. Prog Lipid Res. 2011;50(1):14-27.

89. Miyoshi H, Souza SC, Zhang HH, et al. Perilipin promotes hormone-sensitive lipase-mediated adipocyte lipolysis via phosphorylation-dependent and -independent mechanisms. J Biol Chem. 2006;281(23):15837-15844.

90. Ahmadian M, Duncan RE, Sul HS. The skinny on fat: lipolysis and fatty acid utilization in adipocytes. Trends Endocrinol Metab 2009;20(9):424-428.

91. Irigaray $\mathrm{P}$, Ogier V, Jacquenet $\mathrm{S}$, et al. Benzo[a]pyrene impairs betaadrenergic stimulation of adipose tissue lipolysis and causes weight gain in mice. A novel molecular mechanism of toxicity for a common food pollutant. FEBS J. 2006;273(7):1362-1372.

92. Baker NA, Karounos M, English V, et al. Coplanar polychlorinated biphenyls impair glucose homeostasis in lean C57BL/6 mice and mitigate beneficial effects of weight loss on glucose homeostasis in obese mice. Environ Health Perspect. 2013;121(1):105-110.

93. Baker NA, Shoemaker R, English V, et al. Effects of adipocyte aryl hydrocarbon receptor deficiency on PCB-induced disruption of glucose homeostasis in lean and obese mice. Environ Health Perspect. 2015;123(10):944-950.

94. Nishiumi S, Yoshida M, Azuma T, Yoshida K, Ashida H. 2,3,7,8-tetrachlorodibenzo-p-dioxin impairs an insulin signaling pathway through the induction of tumor necrosis factor-alpha in adipocytes. Toxicol Sci. 2010;115(2):482-491.

95. Panda S. Circadian physiology of metabolism. Science. 2016;354(6315): 1008-1015.

96. Buijs RM, la Fleur SE, Wortel J, et al. The suprachiasmatic nucleus balances sympathetic and parasympathetic output to peripheral organs through separate preautonomic neurons. J Comp Neurol. 2003;464(1):36-48

97. Kalsbeek A, Foppen E, Schalij I, et al. Circadian control of the daily plasma glucose rhythm: an interplay of GABA and glutamate. PLoS One. 2008;3(9):e3194.

98. Balsalobre A, Brown SA, Marcacci L, et al. Resetting of circadian time in peripheral tissues by glucocorticoid signaling. Science. 2000;289(5488):2344-2347.

99. Peschke E. Melatonin, endocrine pancreas and diabetes. J Pineal Res. 2008;44(1):26-40.

100. Peschke E, Wolgast S, Bazwinsky I, Pönicke K, Muhlbauer E. Increased melatonin synthesis in pineal glands of rats in streptozotocin induced type 1 diabetes. J Pineal Res. 2008;45(4):439-448.

101. Mulder H, Nagorny CL, Lyssenko V, Groop L. Melatonin receptors in pancreatic islets: good morning to a novel type 2 diabetes gene, Diabetologia. 2009;52(7):1240-1249.

102. Prasai MJ, Pernicova I, Grant PJ, Scott EM. An endocrinologist's guide to the clock. J Clin Endocrinol Metab. 2011;96(4):913-922.

103. Turek FW, Joshu C, Kohsaka A, et al. Obesity and metabolic syndrome in circadian Clock mutant mice. Science. 2005;308(5724):1043-1045.

104. Marcheva B, Ramsey KM, Buhr ED, et al. Disruption of the clock components CLOCK and BMAL1 leads to hypoinsulinaemia and diabetes. Nature. 2010;466(7306):627-631.

105. Dallmann R, Weaver DR. Altered body mass regulation in male mPeriod mutant mice on high-fat diet. Chronobiol Int. 2010;27(6):1317-1328.

106. Englund A, Kovanen L, Saarikoski ST, et al. NPAS2 and PER2 are linked to risk factors of the metabolic syndrome. J Circadian Rhythms. 2009;7:5

107. Lamia KA, Storch KF, Weitz CJ. Physiological significance of a peripheral tissue circadian clock. Proc Natl Acad Sci U S A. 2008;105(39): $15172-15177$.

108. Pan A, Schernhammer ES, Sun Q, Hu FB. Rotating night shift work and risk of type 2 diabetes: two prospective cohort studies in women. PLoS Med. 2011;8(12):e1001141.

109. Karlsson BH, Knutsson AK, Lindahl BO, Alfredsson LS. Metabolic disturbances in male workers with rotating three-shift work. Results of the WOLF study. Int Arch Occup Environ Health. 2003;76(6):424-430.
110. Barclay JL, Husse J, Bode B, et al. Circadian desynchrony promotes metabolic disruption in a mouse model of shiftwork. PLoS One. 2012;7(5):e37150.

111. Salgado-Delgado R, Angeles-Castellanos M, Buijs MR, Escobar C. Internal desynchronization in a model of night-work by forced activity in rats. Neuroscience. 2008;154(3):922-931.

112. Arble DM, Bass J, Laposky AD, Vitaterna MH, Turek FW. Circadian timing of food intake contributes to weight gain. Obesity (Silver Spring). 2009;17(11):2100-2102.

113. Anderson G, Beischlag TV, Vinciguerra M, Mazzoccoli G. The circadian clock circuitry and the AHR signaling pathway in physiology and pathology. Biochem Pharmacol. 2013;85(10):1405-1416.

114. Shimba S, Watabe Y. Crosstalk between the AHR signaling pathway and circadian rhythm. Biochem Pharmacol. 2009;77(4): 560-565.

115. Garrison PM, Denison MS. Analysis of the murine AhR gene promoter. J Biochem Mol Toxicol. 2000;14(1):1-10.

116. Zhang YK, Yeager RL, Klaassen CD. Circadian expression profiles of drug-processing genes and transcription factors in mouse liver. Drug Metab Dispos. 2009;37(1):106-115.

117. Richardson VM, Santostefano MJ, Birnbaum LS. Daily cycle of bHLH-PAS proteins, Ah receptor and Arnt, in multiple tissues of female Sprague-Dawley rats. Biochem Biophys Res Commun. 1998;252(1):225-231.

118. Huang P, Ceccatelli S, Rannug A. A study on diurnal mRNA expression of CYP1A1, AHR, ARNT, and PER2 in rat pituitary and liver. Environ Toxicol Pharmacol. 2002;11(2):119-126.

119. Mukai M, Lin TM, Peterson RE, Cooke PS, Tischkau SA. Behavioral rhythmicity of mice lacking AhR and attenuation of light-induced phase shift by 2,3,7,8-tetrachlorodibenzo-p-dioxin. J Biol Rhythms. 2008;23(3):200-210.

120. Tanimura N, Kusunose N, Matsunaga N, Koyanagi S, Ohdo S. Aryl hydrocarbon receptor-mediated Cyplal expression is modulated in a CLOCK-dependent circadian manner. Toxicology. 2011;290(2-3): 203-207.

121. Qu X, Metz RP, Porter WW, Cassone VM, Earnest DJ. Disruption of clock gene expression alters responses of the aryl hydrocarbon receptor signaling pathway in the mouse mammary gland. Mol Pharmacol. 2007;72(5):1349-1358.

122. Qu X, Metz RP, Porter WW, Cassone VM, Earnest DJ. Disruption of period gene expression alters the inductive effects of dioxin on the AhR signaling pathway in the mouse liver. Toxicol Appl Pharmacol. 2009;234(3):370-377.

123. Qu X, Metz RP, Porter WW, Neuendorff N, Earnest BJ, Earnest DJ The clock genes period 1 and period 2 mediate diurnal rhythms in dioxin-induced Cyp1A1 expression in the mouse mammary gland and liver. Toxicol Lett. 2010;196(1):28-32.

124. Claudel T, Cretenet G, Saumet A, Gachon F. Crosstalk between xenobiotics metabolism and circadian clock. FEBS Lett. 2007;581(19): 3626-3633.

125. Wang C, Zhang ZM, Xu CX, Tischkau SA. Interplay between Dioxinmediated signaling and circadian clock: a possible determinant in metabolic homeostasis. Int J Mol Sci. 2014;15(7):11700-11712.

126. Jaeger C, Tischkau SA. Role of aryl hydrocarbon receptor in circadian clock disruption and metabolic dysfunction. Environ Health Insights. 2016;10:133-141.

127. Mukai M, Tischkau SA. Effects of tryptophan photoproducts in the circadian timing system: searching for a physiological role for aryl hydrocarbon receptor. Toxicol Sci. 2007;95(1):172-181.

128. Garrett RW, Gasiewicz TA. The aryl hydrocarbon receptor agonist 2,3,7,8-tetrachlorodibenzo-p-dioxin alters the circadian rhythms, quiescence, and expression of clock genes in murine hematopoietic stem and progenitor cells. Mol Pharmacol. 2006;69(6): 2076-2083.

129. Xu CX, Wang C, Krager SL, Bottum KM, Tischkau SA. Aryl hydrocarbon receptor activation attenuates Per1 gene induction and influences circadian clock resetting. Toxicol Sci. 2013;132(2):368-378. 
130. Jaeger C, Xu C, Sun M, Krager S, Tischkau SA. Aryl hydrocarbon receptor-deficient mice are protected from high fat diet-induced changes in metabolic rhythms. Chronobiol Int. 2017;34(3):318-336.

131. Jaeger C, Khazaal AQ, Xu C, Sun M, Krager SL, Tischkau SA. Aryl hydrocarbon receptor deficiency alters circadian and metabolic rhythmicity. J Biol Rhythms. 2017;32(2):109-120.
132. Trask HW, Cowper-Sal-lari R, Sartor MA, et al. Microarray analysis of cytoplasmic versus whole cell RNA reveals a considerable number of missed and false positive mRNAs. RNA. 2009;15(10):1917-1928.

133. Masri S, Papagiannakopoulos T, Kinouchi K, et al. Lung adenocarcinoma distally rewires hepatic circadian homeostasis. Cell. 2016;165(4): 896-909.
The Journal of Receptor, Ligand and Channel Research is an international, peer reviewed, open access, online journal. The journal welcomes laboratory and clinical findings in the fields of biological receptors, ligands, channel and signal transduction research including: receptors and signalling; ligands; transporters, pores and channels; binding and activation; receptor regulation; role of receptors in diseases and their treatment; molecular basis of membrane structure and functions; molecular models of membranes. The manuscript management system is completely online and includes a very quick and fair peer-review system. Visit http://www.dovepress.com/ testimonials.php to read real quotes from published authors.

Submit your manuscript here: https://www.dovepress.com/journal-of-receptor-ligand-and-channel-research-journal 